\section{A Note on Urea Estimation by Diacetyl Monoxime}

\section{J. T. WEARNE}

\author{
From the Biochemistry Department, Royal Perth \\ Hospital, Western Australia
}

(RECEIVED FOR PUBLICATION NOVEMBER 19, 1957)

Rosenthal (1955) has described in great detail a method using diacetyl monoxime which is generally satisfactory for the routine estimation of urea in blood and urine except that complete colour development requires prolonged heating in boiling water. This disadvantage can be overcome by the use of a pressure cooker.

The tubes of reaction mixture are immersed in a beaker filled with hot water to a level above that of the liquid in the tubes. The beaker is placed in a domestic pressure cooker which has been warmed during the preparation of the reaction tubes, heated until all air is expelled, and heating continued for 10 minutes at $15 \mathrm{lb}$. steam pressure. Heating is then stopped, the pressure allowed to fall to zero, and the tubes removed and cooled.

Further heating produced no increase of colour. The colour produced appears more stable. There was approximately $3 \%$ fading in one hour under fluorescent light and $12 \%$ on standing for two days.

One of the reagents (arsenic acid in concentrated hydrochloric acid) is unpleasant and difficult to dispense accurately and the final reaction mixture has a sickly smell. The range, for $0.1 \mathrm{ml}$. of blood and $10 \mathrm{ml}$. final volume, is $0-200 \mathrm{mg}$. urea $/ 100 \mathrm{ml}$.

On the credit side, in comparison with the usual urease-nesslerization methods are greater sensitivity and colour stability as well as greater reagent stability and a shorter time for the analysis.

\section{REFERENCE}

Rosenthal, H. L. (1955). Analyt. Chem., 27, 1980.

\section{A Rotary Drier for Use in the Dry Ashing Method for Estimating Plasma Protein-bound Iodine}

\section{P. LOCKWOOD}

From the Mental Hospitals' Group Laboratory, West Park Hospital, Epsom, Surrey

(RECEIVED FOR PUBLICATION SEPTEMBER 24, 1957)

In the method of Grossmann and Grossmann (1955) for estimating plasma protein-bound iodine, the proteins are precipitated with zinc hydroxide, mixed with alkali, and dried at $95^{\circ} \mathrm{C}$. overnight. This has two disadvantages: drying is slow and zinc ions have an adverse effect on the catalytic coefficient of iodide (Acland, 1957). To avoid these disadvantages Halkerston (1956), following Zieve, Vogel, and Schultz (1955) and others, used "de-acidite FF" ("permutit") to absorb inorganic iodine from the plasma and then dried the plasma with alkali. This had still the disadvantage of a slow drying process, giving a hard, thick mass on the bottom of the tube which was difficult and tedious to leach. To overcome these difficulties, it was suggested that rotating the tubes under some source of heat, such as infra-red lamps, would cause the contents to spread in a thin layer up the walls of the tube, so that drying and leaching would be facilitated.

The apparatus shown in the figures was made for this purpose. On a wooden base, $50 \mathrm{~cm}$. $\times 20 \mathrm{~cm}$., a "matburn" (blood bottle) rotary mixer is attached by a hinge at the front, and a slotted brass strip and wing nut at the rear. The tilt of the turntable is thus adjustable, from $45^{\circ}$ from the horizontal (the normal angle) to vertical. The bottle clips are removed from the turntable and to the latter is bolted an asbestos mat and to the mat a metal canister of bright tinned steel, $18 \mathrm{~cm} . \times 12 \mathrm{~cm}$. diameter. Two rows of $\frac{1}{2}$ in. Terry clips are bolted on the inside of this container to hold 126 in. $\times \frac{5}{8}$ in. pyrex thickwalled test tubes.

A retort stand rod bolted to one corner of the baseboard carries a 340-watt electric bunsen* held in a retort stand boss by means of a bolt or a clamp rod screwed into the side of the base of the bunsen. A tumbler switch, mounted on the base-board, controls the electric supply to the bunsen.

The test tubes containing resin-treated plasma and alkali are placed in the clips inside the canister, the turntable is tilted slightly, and the machine is switched on so that the turntable and canister rotate. The heater is adjusted to point into the canister and its

*Bunray electric bunsen burner type 300 (catalogue No. 3051) supplied by Shandon Scientific Co. Ltd., 6, Cromwell Place, London. S.W.T. 


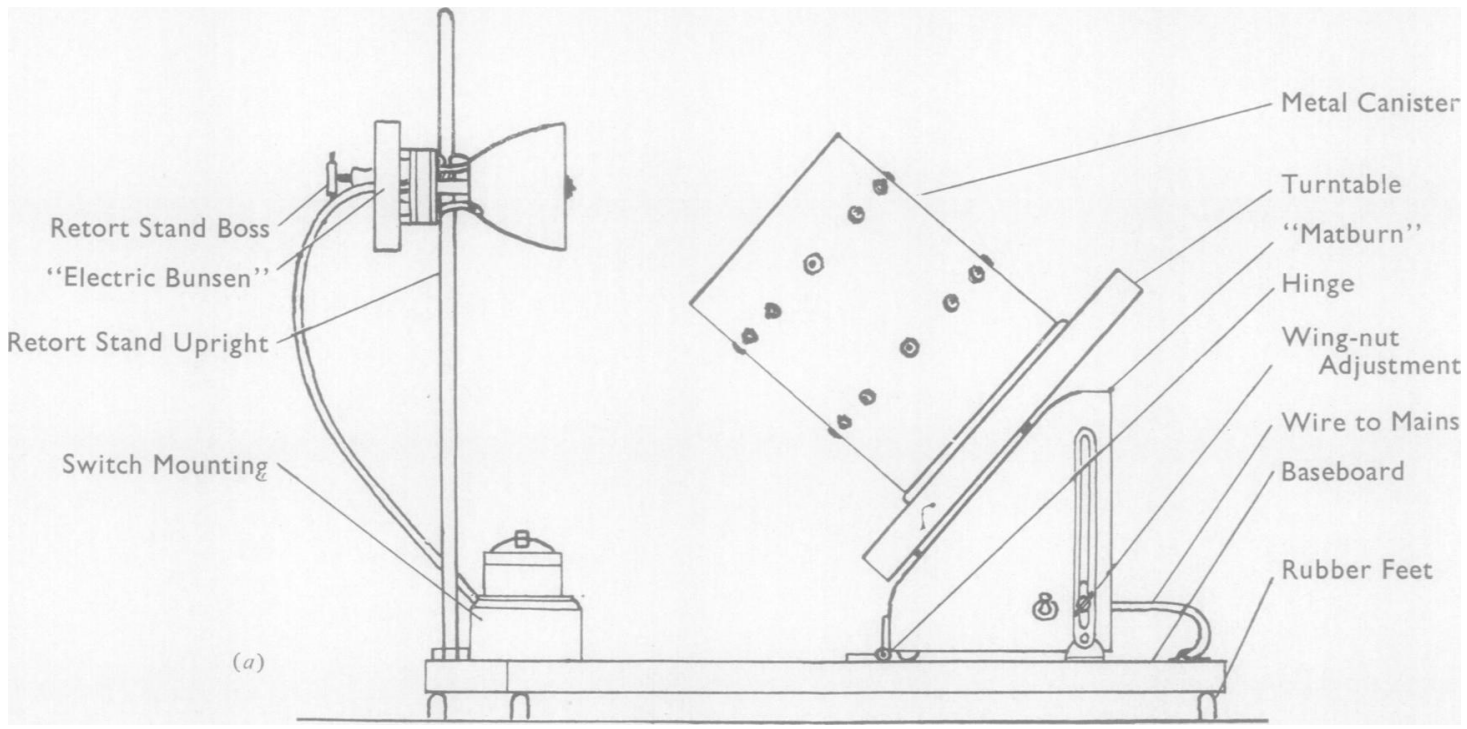

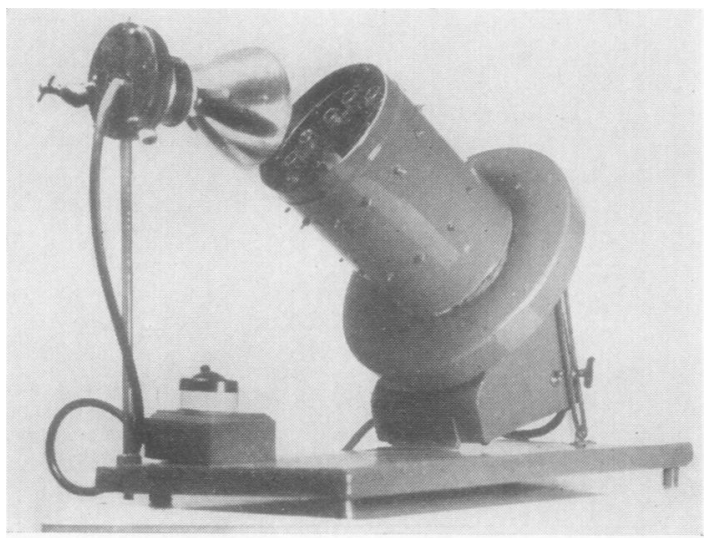

(b)

heater is switched on. Care must be exercised in the first stages of the drying process, for if the tubes are tilted too much when their contents are still very fluid, losses may occur owing to overheating and consequent spattering. As drying progresses, however. the canister can be brought into a position approaching the horizontal, in which position it will present the tubes more closely to the heater.
FIG. 1.-(a) Diagram of the rotary drier, and $(b)$ photograph of the assembly.

In use over several months the apparatus has proved very satisfactory. The plasma and alkali mixture in the tubes is usually spread to a distance of 3 to $4 \mathrm{~cm}$. up the walls of the tubes, and drying is complete in four hours. Leaching after incineration is very easy. entailing only a little scraping with a glass rod, if the acid is allowed to stand in the tubes for a short time.

Some difficulty was at first experienced in the lubrication of the turntable spindle. It was found that silicone fluid D.C.550 applied occasionally was satisfactory and withstood the heating far better than a light-grade mineral oil.

The outside of the canister should preferably be kept bright to reduce heat loss.

My thanks are due to Dr. W. W. Kay, Group Pathologist, for helpful suggestions and to $\mathrm{Mr}$. $\mathrm{P}$. Shackcloth, F.I.M.L.T.. for the photograph.

\section{REFERENCES}

Acland. J. D. (1957). Biochem. J., 66, 177

Grossmann, A., and Grossmann, G. F. (1955). J. clin. Endocr., 15. 354 .

Halkerston, I. D. K. (1956). Personal communication.

Zieve, L., Vogel, W., and Schultz, A. (1955). Clin. Res. Proc., 3, 120 